\title{
Removal of Procalcitonin and Selected Cytokines during Continuous Veno-Venous Hemodialysis Using High Cutoff Hemofilters in Patients with Sepsis and Acute Kidney Injury
}

\author{
Grzegorz Kade $^{a}$ Sławomir Literacki ${ }^{b} \quad$ Agnieszka Rzeszotarska ${ }^{c}$ \\ Stanisław Niemczyk ${ }^{\text {a }}$ Arkadiusz Lubas ${ }^{\text {a }}$ \\ a Department of Internal Diseases, Nephrology and Dialysis, Military Institute of Medicine, Warsaw, Poland; \\ ${ }^{\mathrm{b}}$ Department of Laboratory Diagnostics, Military Institute of Medicine, Warsaw, Poland; ${ }^{\mathrm{C}}$ Department of Clinical \\ Transfusion, Military Institute of Medicine, Warsaw, Poland
}

\section{Keywords}

Sepsis · Cytokines · Procalcitonin · C-reactive protein · Acute kidney injury $\cdot$ High cutoff veno-venous hemodialysis

\begin{abstract}
Introduction: The purpose of this study was to evaluate the impact of continuous veno-venous hemodialysis (CVVHD) using high cutoff ( $\mathrm{HCO}$ ) hemofilters on the removal of procalcitonin (PCT), and other inflammatory markers in the treatment of patients during septic shock with acute kidney injury (AKI). Materials and Methods: Thirty-six patients with septic shock and AKI were included in the study. Before and after the 24-h HCO-CVVHD, PCT, native C-reactive protein (CRP) and cytokines (interleukin-1 $\beta$, interleukin-6, interleukin-12, interleukin-17, tumor necrosis factor- $\alpha$ ) in serum and effluent were assessed. Results: After the HCO-CVVHD serum concentrations of $P C T, C R P$ and selected cytokines were
\end{abstract}

significantly lower. The decrease in PCT was bigger than in $\operatorname{CRP}(p=0.007)$. The change in PCT concentration was significantly influenced by PCT and IL-17 clearances $\left(R^{2}=0.525\right.$; $p<0.001)$. Conclusion: In contrast to the native CRP, monitoring of PCT during HCO-CVVHD is less useful because it reflects the clearance of this marker and anti-inflammatory effectiveness of the method.

(c) 2018 S. Karger AG, Basel

\section{Background}

Sepsis is the body's overwhelming and life-threatening response to infection that can lead to tissue damage, organ failure, and death. Acute kidney injury (AKI) is a frequent complication of sepsis syndrome and is associated with a very high mortality for the patients affected [1]. Continuous renal replacement therapy is a

\section{KARGER}

(c) 2018 S. Karger AG, Basel

E-Mail karger@karger.com

www.karger.com/bpu
Arkadiusz Lubas

Department of Internal Diseases, Nephrology and Dialysis

Military Institute of Medicine, ul.

Szaserów 128, PL-04-141 Warsaw (Poland)

E-Mail alubas@wim.mil.pl 
potential method of extracorporeal removal of inflammatory mediators in septic patients. Procalcitonin (PCT) levels have been shown to be closely correlated with the course and the outcome of patients with several bacterial infections and sepsis $[2,3]$. In the available literature, studies on the influence of continuous veno-venous hemodialysis with high cutoff hemofilters (HCO-CVVHD) on concentrations of PCT, serum C-reactive protein (CRP), hypoxia-inducible factor 1-alpha (HIF1- $\alpha$ ) and cytokines in the blood serum are few and concern individual cases or small numbers of patients. We present the impact of HCO-CVVHD on the removal of PCT, CRP, and selected cytokines in the treatment of patients during sepsis with multiple organ failure, including AKI.

\section{Material and Methods}

The study included 36 patients $(20 \mathrm{M}+16 \mathrm{~F}$, age $61.8 \pm 15.3)$ in septic shock and AKI stage 3, treated with HCO-CVVHD. The clinical diagnosis of septic shock and AKI was done according to the criteria of surviving sepsis campaign and Kidney Disease: Improving Global Outcomes $[1,4]$. In all patients, the Sequential Organ Failure Assessment (SOFA) score was assessed (Table 1) [5]. All of the patients in the group received a standard therapy.

Due to the growth of organ dysfunction, including AKI, the patients were subjected to 24-h HCO-CVVHD using a hemofilter with Polyarylethersulfone (PAES) membrane (effective surface area $1.1 \mathrm{~m}^{2}$; cutoff $45 \mathrm{kDa}$ ), allowing for the removal of cytokines (septeX ${ }^{\mathrm{TM}}$, Gambro Lundia AB, Sweden). CVVHD was started within $12 \mathrm{~h}$ from the diagnosis of septic AKI. The blood flow rate $\left(\mathrm{Q}_{\mathrm{B}}\right)$ was averagely $150 \mathrm{~mL} / \mathrm{min}$, while the dialysate flow rate $\left(Q_{D}\right.$ - volume of dialysis fluid running into the circuit per unit of time) was $1,200 \mathrm{~mL} / \mathrm{h}$. Net ultrafiltration (QUF ${ }^{\mathrm{NET}}$ - volume removed from the patient by the machine per unit of time) was $100 \mathrm{~mL} / \mathrm{h}$ on average. For anticoagulatory support, the replacement flow rate in pre-dilution $\left(\mathrm{Q}_{\mathrm{R}}{ }^{\mathrm{PRE}}\right)$ was $250 \mathrm{~mL} / \mathrm{h}[6]$. Anticoagulation was performed using unfractionated heparin or, if severe coagulation disorders occurred, anticoagulation was performed only by flushing with $0.9 \% \mathrm{NaCl}$. Before the start of dialysis and after $24 \mathrm{~h}$ of treatment, the concentration levels of selected cytokines (tumor necrosis factor [TNF- $\alpha$ ]; Interleukin$1 \beta$ [IL-1 $\beta$ ]; interleukin-6 [IL-6], interleukin-12 [IL-12], interleukin-17 [IL-17]) in the serum were assessed. After $24 \mathrm{~h}$ of treatment, the concentration of the same cytokines in the dialysis fluid was assessed. The method of cytokine concentration assessment was described before [3]. The detection limit of concentrations of individual cytokines was as follows: total TNF- $\alpha$ (monomer $17 \mathrm{kDa}$; trimer $-51 \mathrm{kDa}) 0-8.5 \mathrm{pg} / \mathrm{mL}$; IL- $1 \beta(17.5 \mathrm{kDa}) 0-0.63 \mathrm{pg} /$ $\mathrm{mL}$; IL-6 (21 kDa) 0-10.5 pg/mL; IL-12 (75 kDa) 0-2.5 pg/mL; IL-17 (20 kDa) 0-1.2 pg/mL.

Before the start of dialysis and after $24 \mathrm{~h}$ of treatment, the PCT serum concentration $(13 \mathrm{kDa})$ was assessed. PCT was measured in effluent $24 \mathrm{~h}$ after the initiation of HCO-CVVHD. PCT assays were performed with the Elecsys BRAHMS PCT test using the Cobas e411 analyzer (Roche Diagnostics). The test is based on the
Table 1. Basic characteristics of the study group

\begin{tabular}{lc}
\hline Data & Value \\
\hline Age, years & $61.8 \pm 15.3$ \\
Gender, male + female & $20+16$ \\
Weight, kg & $78.28 \pm 21.56$ \\
Creatinine, mg/dL & $2.97 \pm 1.78$ \\
SOFA & $14.7 \pm 4.3$ \\
\hline
\end{tabular}

SOFA, sequential organ failure assessment.

electro-chemiluminescence immunoassay method. The measurement is the reaction of an antigen present in a tested sample with monoclonal antibodies specific for PCT. The measuring range is $0.02-100 \mathrm{ng} / \mathrm{mL}$. The assays were performed based on the procedure provided by the analyzer manufacturer.

CRP concentrations were measured by latex-enhanced immunoturbidimetric assays. In this method, a pentameric (native) form of CRP (115 kDa) agglutinates with latex particles coated with monoclonal antibodies against human CRP. The standard reference range for adults is less than $0.5 \mathrm{mg} / \mathrm{dL}$.

The Therumo Scientific HIF1- $\alpha$ ELISA Kits were used to measure the concentration of HIF1- $\alpha$. The methodology of the assay uses a quantitative sandwich ELISA test. The assay was made according to the instructions of the manufacturer. In order to ensure optimum conditions during the assay, the Stat Fax 2200 incubator/ shaker from Awareness Technology, the ETI-System DiaSorin washers and the BioTek ELx 800 reader were used. The reference range of HIF1- $\alpha$ is $0-2.4 \mathrm{pg} / \mathrm{mL}$. Clearances $(\mathrm{mL} / \mathrm{min})$ of investigated substances were calculated with the formula:

$$
\left(\mathrm{Q}_{\mathrm{D}}+\mathrm{Q}_{\mathrm{UF}}{ }^{\mathrm{NET}}+\mathrm{Q}_{\mathrm{R}}{ }^{\mathrm{PRE}}\right) / 60 \times \mathrm{CF}_{24} / \mathrm{C}_{24}
$$

where $\mathrm{C}_{24}$ and $\mathrm{CF}_{24}$ are the serum and fluid substance concentration after $24 \mathrm{~h}$ of HCO-CVVHD.

\section{Ethical Approval}

The research related to human use has been complied with all the relevant national regulations, institutional policies, and in accordance with the tenets of the Helsinki Declaration. The protocol of the study was approved by the local Bioethics Committee. Due to the observational nature of the analysis that used only anonymised parameters, no individual written consent was required.

\section{Statistical Analysis}

The Statistica 12 (StatSoft Inc.) software was used. The data with normal distribution were presented as mean and $\mathrm{SD}$, otherwise as a median with minimal and maximal value. The differences between results before and after HCO-CVVHD were analyzed with the Wilcoxon test for paired samples as determined by missing the condition of normal distribution. The relations between investigated variables were tested with the Spearman's correlation test. The performed tests were considered significant if $p$ value $<0.05$. The change of substance concentration during HCO-CVVHD was calculated as the difference of pre- and post-treatment concentrations then divided to pre-treatment and expressed as percentage value, so that positive result indicated lowered concentration dur- 
Table 2. Inflammatory markers and mediators before and after $24 \mathrm{~h}$ of treatment

\begin{tabular}{|c|c|c|c|c|c|c|}
\hline & $\mathrm{C}_{0}$ & $\mathrm{C}_{24}$ & Change, $\%$ & $\mathrm{CF}_{24}$ & $\mathrm{CL}_{24}, \mathrm{~mL} / \mathrm{min}$ & $\begin{array}{l}p \text { value } \\
\left(\mathrm{C}_{0}-\mathrm{C}_{24}\right)\end{array}$ \\
\hline PCT, ng/mL & $28.50^{\#}(2.41-240.18)$ & $14.38^{\#}(0.36-203.00)$ & $38.34 \pm 35.26$ & $22.44^{\#}(0.07-101.50)$ & $23.26^{\#}(0.03-150.00)$ & $<0.001$ \\
\hline $\mathrm{CRP}, \mathrm{mg} / \mathrm{dL}$ & $19.90 \pm 12.07$ & $16.40 \pm 10.78$ & $11.30^{\#}(-37.50$ to 64.44$)$ & $\mathrm{n} / \mathrm{a}$ & $\mathrm{n} / \mathrm{a}$ & $<0.001$ \\
\hline HIF $1-\alpha^{\#}, p g / m L$ & $0.48(0.10-57.35)$ & $0.31(0.04-66.32)$ & $11.67(-18,090.91$ to 99.65$)$ & $\mathrm{n} / \mathrm{a}$ & $\mathrm{n} / \mathrm{a}$ & 0.850 \\
\hline $\mathrm{IL}-1 \beta^{\#}, \mathrm{pg} / \mathrm{mL}$ & $1.53(0.02-16.10)$ & $1.28(0.07-14.92)$ & $4.75(-1,104.35$ to 94.53$)$ & $0.45(0.10-52.54)$ & $25.83(1.23-240.25)$ & 0.016 \\
\hline IL-6 $6^{\#}, \mathrm{pg} / \mathrm{mL}$ & $836.28(61.75-7,668.47)$ & $802.27(57.44-4,003.44)$ & $35.37(-488.91$ to 83.76$)$ & $322.71(34.91-8,844.59)$ & $18.83(3.80-71.87)$ & 0.011 \\
\hline $\mathrm{IL}-12^{\#}, \mathrm{pg} / \mathrm{mL}$ & $1.17(0.00-38.02)$ & $1.26(0.00-26.63)$ & $2.44(-428.83$ to 100.00$)$ & $1.10(0.00-1.13)$ & $3.01(0.00-38.75)$ & 0.123 \\
\hline $\mathrm{IL}-17^{\#}, \mathrm{pg} / \mathrm{mL}$ & $2.22(0.00-17.77)$ & $2.34(0.07-18.03)$ & $21.31(-162.50$ to 85.33$)$ & $0.45(0.03-23.53)$ & $12.92(0.00-118.10)$ & 0.084 \\
\hline TNF- $\alpha^{\#}, p g / m L$ & $17.24(0.10-84.65)$ & $9.23(0.10-50.24)$ & $33.01(-3,120.00$ to 79.52$)$ & $2.36(0.10-54.64)$ & $16.13(0.19-75.44)$ & $<0.001$ \\
\hline
\end{tabular}

$\mathrm{C}_{0}$, serum substance concentration before $\mathrm{HCO}-\mathrm{CVVHD} ; \mathrm{C}_{24}$, serum substance concentration after $24 \mathrm{~h}$ of $\mathrm{HCO}-\mathrm{CVVHD}_{2} \mathrm{CF}_{24}$, substance concentration in the dialytic fluid after $24 \mathrm{~h}$ of HCO-CVVHD; $\mathrm{CL}_{24}$, clearance of substance after $24 \mathrm{~h}$ of HCO-CVVHD; CRP, C-reactive protein; HIF1- $\alpha$, hypoxia inducible factor 1- $\alpha$; IL, interleukin; PCT, procalcitonin; TNF- $\alpha$, tumor necrosis factor $\alpha .{ }^{\#}$ Median.

ing the procedure. Linear stepwise regression analysis was used to determine independent factors influencing PCT variability during the HCO-CVVHD.

For the estimation of the sample size, the data from 10 initially investigated patients were analyzed with paired $t$ test for dependent variables. A sample size necessary to achieve significance $(p<$ 0.05) between PCT and CRP change during HCO-CVVHD ( $54.57 \pm 29.08$ vs. $14.04 \pm 26.34 \%$, respectively) was 12 patients for the statistical power of the test of $>0.9$.

\section{Results}

In the study group, the mean SOFA score was $14.7 \pm$ 4.3 (Table 1). In the course of HCO-CVVHD treatment during the hospitalization, 30 patients died, including $24(80 \%)$ due to sepsis and $6(20 \%)$ due to other causes (bleeding, heavy pneumonia, pulmonary embolism). Six patients were discharged from the hospital to outpatient care. Mean concentrations of inflammatory markers (PCT and CRP) as well as most of the proinflammatory cytokines (except IL-12 and IL-17) in the serum, decreased significantly during the HCO-CVVHD (Table 2).

The initial IL-17 concentration significantly correlated with IL-1 $\beta(r=0.333, p<0.05)$, IL-12 $(r=0.391, p<$ $0.05)$, and TNFa $(r=0.606, p<0.05)$, preserving the above relationships after the HCO-CVVHD $(r=0.350$, $p<0.05 ; r=0.338, p<0.05 ; r=0.620, p<0.05$ respectively).

IL-17 clearance during the HCO-CVVHD significantly correlated with IL-1 $\beta(r=0.525 ; p<0.05)$ and IL-12 clearances $(r=0.497 ; p<0.05)$. Moreover, there was a significant positive correlation between IL-6 and TNFa clearances $(r=0.455, p<0.05)$. The clearance of the marked substances (cytokines and PCT) correlated with their molecular weight $(r=-0.87, p=0.024$; Fig. 1).

The change in IL-17 concentration during the HCOCVVHD was associated with the initial CRP concentration $(r=0.369, p<0.05)$, change in PCT level $(r=0.385$, $p<0.05)$, final PCT concentration $(r=-0.394, p<0.05)$, SOFA score $(r=0.350, p<0.05)$, and mortality due to sepsis $(r=0.345, p<0.05)$. In addition to the above-mentioned correlations, the relationships of CRP with other parameters were rare: the initial CRP concentration correlated significantly only with the change in CRP concentration $(r=0.380, p<0.05)$ and its post-treatment concentration $(r=0.901, p<0.05)$.

There were no significant correlations between the concentrations of PCT, both initial and post-treatment with appropriate concentrations of the marked cytokines and CRP. Furthermore, there were no correlations between the PCT clearance and the marked clearances of proinflammatory cytokines during the HCO-CVVHD. However, a significant correlation between the PCT clearance and the change in IL-12 concentration during the treatment was found $(r=0.393, p<0.05)$. Additionally, the change in PCT concentration during the HCOCVVHD was significantly associated with the posttreatment PCT value $(r=-0.514, p<0.05)$, PCT clearance $(r=0.525, p<0.05)$ and the aforementioned change in IL-17 concentration.

Although the change in PCT level during the HCOCVVHD was significantly higher than the change in CRP concentration $(38.34 \pm 35.26$ vs. $11.30 \%$ [ -37.50 to $64.44 \%$ ]; $p=0.007$; with the statistical power of 0.91 for the probability of type I error $=0.05)$, PCT before and after the $24 \mathrm{~h} \mathrm{HCO-CVVHD}$, their changes during the 
Fig. 1. Linear regression diagram showing the relation of clearances with molecular masses of the analyzed substances. Dotted lines express $-95 \%$ and $+95 \%$ confidence interval.

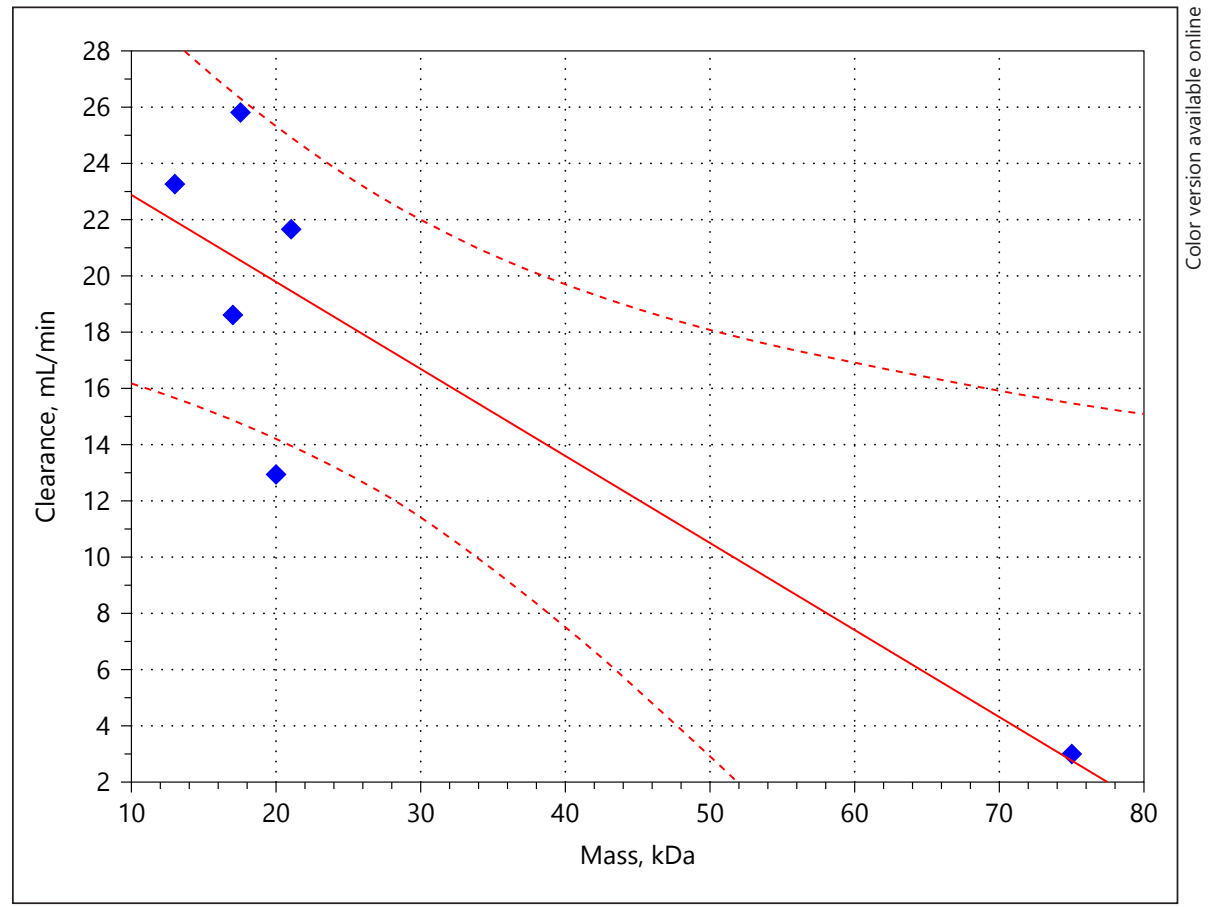

treatment, as well as the clearance of PCT were not significantly associated with the SOFA score, mortality due to sepsis, and total mortality.

In the multivariable regression analysis that took into account the clearances of PCT, IL-12, IL-17, and the change in CRP concentration that may have been responsible for the change in the PCT level during the HCO-CVVHD, it was shown that the clearances of both PCT and IL-17 were responsible for approximately 52\% PCT variability during the procedure $\left(\mathrm{R}^{2}=0.525, p<\right.$ 0.001 , power 0.999 ).

\section{Discussion}

In this study, a significantly higher decrease of PCT than CRP during the HCO-CVVHD procedure was found. However, as opposed to PCT, the most frequently estimated pentameric (native) form of CRP is not removed during HCO dialysis due to its high mass. These findings suggest that a decrease of PCT during an HCOCVVHD treatment relates to its clearance and in addition, probably to the inflammatory cytokine removal [7]. This hypothesis is supported by the results of our previous and present works, in which a removal of proinflammatory cytokines during the $\mathrm{HCO}-\mathrm{CVVHD}$ was proved [8]. In the performed multivariable regression analysis, we found that PCT and IL-17 clearances independently influence the change in PCT level during the HCO-CVVHD.

In recent years, blood purification therapies have been proposed as an effective therapy to control the dysregulation of cytokines in systemic inflammatory syndromes. Among them, a treatment with high cutoff ( $\mathrm{HCO})$ membranes is characterized by a large pore size and a more effective clearance for middle molecular weight molecules (cytokines). Generally, a sieving coefficient (SC) for albumin over zero should be obtained to define a membrane as HCO. In other words, a cutoff value of at least $60 \mathrm{kDa}$ should be distinctive of these membranes.

PCT, the precursor for the hormone calcitonin, is composed of 116 aminoacids and has a molecular weight of $13 \mathrm{kDa}$. In sepsis, a marked increase of PCT serum concentration has been reported. The role of PCT as a mediator of the sepsis cascade received much less attention. A proinflammatory activity of PCT in the pathogenesis of sepsis has been suggested based on immune-neutralization findings in 2 animal species [9]. A significant reduction of PCT in the serum was observed during the treatment with HCO. Although this effect could be related to the anti-inflammatory effect of the treatment, a direct transmembrane clearance was also observed (SC of 0.45), decreasing the clinical accuracy of PCT as a biomarker of sepsis [7]. 
Studies on the effect of CVVHD using HCO hemofilters (HCO-CVVHD) on the PCT serum concentration in patients with severe sepsis or in septic shock are few and concern individual cases or small numbers of patients. Our study is based on the group of 36 patients, the largest in the Medline database.

One of the first reports on the removal of PCT from the blood serum to a dialysis fluid during continuous veno-venous hemodiafiltration was the case described by Nishikura [10], which found that the amount of the eliminated PCT from the serum was approximately $100 \mathrm{ng} / \mathrm{min}$ and its clearance was $2.3-3.4 \mathrm{~mL} / \mathrm{min}$. In the study by Yaroustovsky et al. [11], the study group included 26 patients with severe sepsis. The aim of this study was to evaluate the effectiveness and safety of the combined use of lipopolysaccharide adsorption and haemodialysis with HCO hemofilters. After the last HD with $\mathrm{HCO}$ hemofilters, PCT decreased from 8.19 to $2.44 \mathrm{ng} / \mathrm{mL}$ (aproximately 70\%). In our group, the mean PCT serum concentration before the procedure $\left(\mathrm{C}_{0}=\right.$ $28.5 \mathrm{ng} / \mathrm{mL}$ ) was about two times higher than after the treatment $\left(\mathrm{C}_{24}=14.3 \mathrm{ng} / \mathrm{mL}\right.$; change of approximately $50 \%)$. In our work, the smaller decrease in PCT was probably associated with a more severe initial inflammation, as evidenced by the initial PCT values.

In a preliminary report, Chelazzi et al. [12] examined the impact of HCO-CVVHD on the PCT serum concentration and the resulting diagnostic and therapeutic effects. The study involved patients with severe sepsis or in septic shock meeting the surviving sepsis campaign guidelines. In each case, the HCO hemofilter (septeX, Gambro Lundia AB, Sweden) was used. PCT was measured in the serum and effluent $0,12,24$, and $48 \mathrm{~h}$ after the initiation of the HCO-CVVHD and an SC was calculated. The obtained median for SC was $0.64 \pm 0.33$ after $12 \mathrm{~h}$; was $0.66 \pm 0.11$ after $24 \mathrm{~h}$; and was $0.75 \pm 0.17$ after $48 \mathrm{~h}$. The calculated SC for PCT was $59-95 \%$ after $48 \mathrm{~h}$ of the HCO-CVVHD. Due to the passage of PCT into the dialysis fluid, the authors considered CRP a useful marker of inflammation dynamics in patients undergoing the HCO-CVVHD. CRP as a large protein does not pass into the dialysis fluid. In our study, it was confirmed that the treatment affected the statistically significant decrease of CRP in the serum. Similar results concerning, among others, CRP were presented by Caldini et al. [13]. In the group of 7 AKI patients with severe sepsis or septic shock, HCO-CVVHDF was performed. Although a decrease in the PCT serum concentration has been observed in all patients (from 89 to $51 \%$ of base values), the authors indicate that the PCT serum concentration during the HCO-CVVHDF should be interpreted with caution. In our group, the mean reduction in PCT serum concentration was $38 \%$, and a positive correlation between the reduction in the PCT serum concentration and the decrease in IL-17 concentration was observed. In the available literature, there are no studies that can relate to our results. At the same time, it is known that IL-17 appears to be a main factor in the human immune system. Proinflammatory cytokines such as IL-6, IL-1 $\beta$, and TNF- $\alpha$, which mediate defensive responses, are induced by IL-17 [14]. In the present study, we found a significant correlation of initial IL-17 concentration with IL-1 $\beta$, IL-12, and TNFa, which proves the correctness of our observations. Moreover, these relations were still observed after HCO-CVVHD, despite lowering serum cytokines concentration. In addition, we found significant correlations between IL-17, IL- $1 \beta$, and IL- 12 clearances during the HCO-CVVHD. These findings suggest unselective cytokine removal during the HCO-CVVHD, and thus, the immunomodulative role of this procedure. In our study, we qualified patients to the HCO-CVVHD treatment under condition of septic shock with AKI stage 3, without considering criteria of early or late phase of the disease. However, the early HCO-CVVHD treatment could be important for better patients' survival, because in the mouse model of experimental sepsis, Flierl et al. [15] showed that neutralization of IL-17 by specific antibodies in the first $12 \mathrm{~h}$ improved survival from 10 to $60 \%$. On the other hand, Wu et al. [16] observed that anti-IL-17 treatment in lipopolysaccharide-stimulated peripheral blood mononuclear cells of patients with severe sepsis significantly decreased IL-12 and increased IL-10 production, which was connected with higher mortality. The authors suggest that early elimination of IL-17 results in improving the survival of patients with sepsis by decreasing systemic inflammation, whereas decrease of IL-17 in the late phase of sepsis could worsen patients' outcome.

During the course of the treatment, we also observed a decrease of HIF1- $\alpha$ concentration in the serum but of no statistical significance. Due to the large size of HIF1- $\alpha$ and CRP molecules, their concentrations in the dialysis fluid were not analyzed. However, in the case of inflammation, the pentameric (native) form of CRP can dissociate into monomeric (modified) CRP (approximately $23 \mathrm{kDa}$ ), which can easily pass through the HCO filter [17]. We did not measure concentrations of the monomeric form of CRP, and this is a limitation of our study. On the other hand, monomeric CRP is generated from native CRP in sites of inflammation, and is rather non- 
soluble and tissue-based (e.g., connected with atherosclerotic plaques) protein; thus, usability of its estimation during HCO-CVVHD procedure in septic shock is disputable and requires further investigation.

Another noteworthy topic is the use of polyarylethersulfone membranes, which are generally considered nonadsorbing; thus, convective transport is the key mechanism for cytokine removal by these $\mathrm{HCO}$ hemofilters. However, we cannot exclude that adsorption contributes to a certain cytokine removal during the HCO-CVVHD.

\section{Conclusions}

CVVHD using HCO hemofilters effectively removes PCT and selected inflammatory cytokines in patients with septic and AKI. Decreased PCT concentrations during HCO-CVVHD show both clearance of this marker and anti-inflammatory effectiveness of the method. The concentrations, clearance, and the change of PCT levels during the HCO-CVVHD do not correlate with the SOFA score, overall mortality, and deaths due to sepsis. In these conditions, serum native CRP concentration appears to be a better marker than PCT and other examined cytokines for the evaluation of an inflammatory state during the HCO-CVVHD.

\section{Disclosure Statement}

The funding organization played no role in the study design; in the collection, analysis, and interpretation of data; in the writing of the report; or in the decision to submit the report for publication.

\section{Employment or Leadership}

None declared.

\section{Honorarium}

None declared.

\section{Research Funding}

Statutory grant number 179 from Polish Ministry of Science and Higher Education.

\section{Author Contributions}

All the authors have accepted responsibility for the entire content of this submitted manuscript and approved submission.

\section{References}

1 Rhodes A, Evans LE, Alhazzani W, Levy MM, Antonelli M, Ferrer R, Kumar A, Sevransky JE, Sprung CL, Nunnally ME, Rochwerg B, Rubenfeld GD, Angus DC, Annane D, Beale RJ, Bellinghan GJ, Bernard GR, Chiche JD, Coopersmith C, De Backer DP, French CJ, Fujishima S, Gerlach H, Hidalgo JL, Hollenberg SM, Jones AE, Karnad DR, Kleinpell RM, Koh Y, Lisboa TC, Machado FR, Marini JJ, Marshall JC, Mazuski JE, McIntyre LA, McLean AS, Mehta S, Moreno RP, Myburgh J, Navalesi P, Nishida O, Osborn TM, Perner A, Plunkett CM, Ranieri M, Schorr CA, Seckel MA, Seymour CW, Shieh L, Shukri KA, Simpson SQ, Singer M, Thompson BT, Townsend SR, Van der Poll T, Vincent JL, Wiersinga WJ, Zimmerman JL, Dellinger RP: Surviving sepsis campaign: international guidelines for management of sepsis and septic shock: 2016. Crit Care Med 2017;45:486-552.

-2 Vijayan AL, Vanimaya, Ravindran S, Saikant R, Lakshmi S, Kartik R, G M: Procalcitonin: a promising diagnostic marker for sepsis and antibiotic therapy. J Intensive Care 2017;5:51.

-3 Ljungström L, Pernestig AK, Jacobsson G, Andersson R, Usener B, Tilevik D: Diagnostic accuracy of procalcitonin, neutrophil-lymphocyte count ratio, C-reactive protein, and lactate in patients with suspected bacterial sepsis. PLoS One 2017;12:e0181704.

4 Kidney Disease: Improving Global Outcomes (KDIGO) Acute Kidney Injury Work Group: KDIGO clinical practice guideline for acute kidney injury. Kidney Int Suppl 2012;2:1138.

5 Vincent JL, de Mendonça A, Cantraine F, Moreno R, Takala J, Suter PM, Sprung CL, Colardyn F, Blecher S: Use of the SOFA score to assess the incidence of organ dysfunction/ failure in intensive care units: results of a multicenter, prospective study. Working group on "sepsis-related problems" of the European Society of Intensive Care Medicine. Crit Care Med 1998;26:1793-1800.

6 Neri M, Villa G, Garzotto F, Bagshaw S, Bellomo R, Cerda J, Ferrari F, Guggia S, Joannidis M, Kellum J, Kim JC, Mehta RL, Ricci Z, Trevisani A, Marafon S, Clark WR, Vincent JL, Ronco C; Nomenclature Standardization Initiative (NSI) alliance; Nomenclature for renal replacement therapy in acute kidney injury: basic principles. Crit Care 2016;20:318.
7 Villa G, Zaragoza JJ, Sharma A, Neri M, De Gaudio AR, Ronco C: Cytokine removal with high cut-off membrane: review of literature. Blood Purif 2014;38:167-173.

$>8$ Kade G, Lubas A, Rzeszotarska A, Korsak J, Niemczyk S: Effectiveness of high cut-off hemofilters in the removal of selected cytokines in patients during septic shock accompanied by acute kidney injury-preliminary study. Med Sci Monit 2016;22:4338-4344.

-9 Matera G, Quirino A, Giancotti A, Pulicari MC, Rametti L, Rodríguez ML, Liberto MC, Focà A: Procalcitonin neutralizes bacterial LPS and reduces LPS-induced cytokine release in human peripheral blood mononuclear cells. BMC Microbiol 2012;12:6876.

10 Nishikura T: The clearance of procalcitonin (PCT) during continuous veno-venous hemodiafiltration (CVVHD). Intensive Care Med 1999;25:1198-1199.

11 Yaroustovsky M, Abramyan M, Krotenko N, Popov D, Plyushch M, Rogalskaya E, Nazarova $\mathrm{H}$ : Combined extracorporeal therapy for severe sepsis in patients after cardiac surgery. Blood Purif 2014;37:39-46. 
12 Chelazzi C, Giannoni C, Villa G, Giugni D, Caldini AL, De Gaudio AR: Plasma Concentrations and Sieving Coefficient of Procalcitonin during Continuous Veno-Venous Haemodialysis with High Cut Off Membranes in Septic Patients: A Preliminary Report. www. esicm.org/upload/Wed_detailed\%20prog(1). pdf.

13 Caldini A, Chelazzi C, Terreni A, Biagioli T, Giannoni C, Villa G, Messeri G, De Gaudio AR: Is procalcitonin a reliable marker of sepsis in critically ill septic patients undergoing continuous veno-venous hemodiafiltration with "high cut-off" membranes (HCO-CVVHDF)? Clin Chem Lab Med 2013;51:e261-e263.

14 Onishi RM, Gaffen SL: Interleukin-17 and its target genes: mechanisms of interleukin-17 function in disease. Immunology 2010;129: 311-321.

15 Flierl MA, Rittirsch D, Gao H, Hoesel LM, Nadeau BA, Day DE, Zetoune FS, Sarma JV, Huber-Lang MS, Ferrara JL, Ward PA: Adverse functions of IL-17A in experimental sepsis. FASEB J 2008;22:2198-2205.

16 Wu HP, Shih CC, Chu CM, Huang CY, Hua CC, Liu YC, Chuang DY: Effect of interleu- kin-17 on in vitro cytokine production in healthy controls and patients with severe sepsis. J Formos Med Assoc 2015;114:1250-1257. 17 Thiele JR, Habersberger J, Braig D, Schmidt Y, Goerendt K, Maurer V, Bannasch H, Scheichl A, Woollard KJ, von Dobschütz E, Kolodgie F, Virmani R, Stark GB, Peter K, Eisenhardt SU: Dissociation of pentameric to monomeric C-reactive protein localizes and aggravates inflammation: in vivo proof of a powerful proinflammatory mechanism and a new anti-inflammatory strategy. Circulation 2014;130:35-50. 